\title{
Diagnostic values of abdominal muscles thickness and sterno-costal angle for young adults with rounded shoulders
}

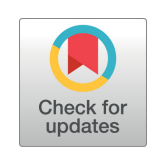

\author{
Chan-hee Lee ${ }^{a(1)}$, Sujin Hwang ${ }^{b(1)}$ \\ ${ }^{a}$ Department of Physical Therapy, Median Hospital, Cheonan, Republic of Korea \\ ${ }^{b}$ Department of Physical Therapy, Division of Health Science, Baekseok University, Cheonan, Republic of Korea
}

Objective: The purposes of this study was to evaluate the diagnostic values of abdominal muscles thickness and sterno-costal angle as the quantitative diagnostic indicators for young adults with rounded shoulders.

Design: A observational, cross-sectional study.

Methods: This study included thirty-three male participants in order to examine the relationship among thoracic kyphosis, sternocostal angle, and abdominal muscle thickness. We used ultrasound imaging to measure the muscle thickness, two gravity-dependent inclinometers to measure the kyphosis angle, and Image $\mathrm{J}$ to measure the sterno-costal angle.

Results: There was a significant positive correlation between the amount of thoracic kyphosis angle and muscle thickness of the external oblique (EO) on the right side $(\mathrm{r}=0.931)$, and on the left side $(\mathrm{r}=0.432)$, and the transverse abdominis $(\operatorname{TrA})(\mathrm{r}=0.649)$. There was also a significant negative correlation between the thoracic kyphosis angle and the sterno-costal angle at the right side $(\mathrm{r}=-0.942)$ and at the left side $(\mathrm{r}=-0.860)$. There was a significant positive relationship with muscle thickness of the EO and TrA on the right side with the thoracic kyphosis angle, and was significant negative relationship with the sterno-costal angle on both sides.

Conclusions: The results of the study suggest that the thoracic kyphosis angle is related to muscle thickness of the EO and TrA on the dominant side and the sterno-costal angle. We also suggest that future studies are needed to determine how strengthening the abdominal muscles may contribute to preventing excessive thoracic kyphosis in young adults.

Key Words: Kyphosis, Muscles, Sternum, Thorax

\section{Introduction}

The kyphotic curve in the spine, as a term used to indicate a posterior curve, is a primary curvature of the vertebral column, with four curvatures including two lordotic curves and two single curves that are convex posteriorly [1]. A normal thoracic spine extends from the 1 st to the 12 th thoracic vertebra and should have a slight kyphotic angle, ranging from 20 to 45 degrees. When the kyphotic angle increases past 45 degrees, it is called "kyphosis" or "hyperkyphosis" and refers to a condition of the "roundness" of the upper trunk part [2]. The excessive posterior curvature of the thoracic kyphosis would cause back pain and discomfort, difficultly breathing, indigestion, as well as cardiovascular and neurological impairments [1].

As mentioned earlier, thoracic kyphosis cause a variety of disorders and secondary complications, but especially limits physical function and impairs body image [3]. Thoracic kyphosis is associated with weakened back muscles of the shoulders and upper back, such as the trapezius, latissimus dorsi, and rhomboids, and with shortened and tight muscles of the pectoralis major and minor muscles and the muscles in the back of neck because of an imbalance of the upper back and neck muscles [3-6]. Therefore, having a kyphosis would make it difficult to perform daily fundamental activities, such as getting out of chairs, walking or eye movement ac-

Received: 11 March, 2020 Revised: 23 March, 2020 Accepted: 24 March, 2020

Corresponding author: Sujin Hwang (ORCID https://orcid.org/0000-0001-8471-0103)

Department of Physical Therapy, Division of Health Science, Baekseok University, 76 Munam-ro, Dongnam-gu, Cheonan 31065 , Republic of Korea Tel: 82-41-550-2309 Fax: 82-41-550-2829 E-mail: ptsue@bu.ac.kr

(c) This is an Open-Access article distributed under the terms of the Creative Commons Attribution Non-Commercial License (http://creativecommons.org/licenses/ by-nc/4.0) which permits unrestricted non-commercial use, distribution, and reproduction in any medium, provided the original work is properly cited.

Copyright ( 2020 Korean Academy of Physical Therapy Rehabilitation Science 
cording to visual or auditory stimulus and also would develop a poor body image from having a rounded back [3-6]. The development of thoracic kyphosis should be prevented because it typically does not respond well to conservative treatment [1,3-6].

In general, $\mathrm{x}$-rays are taken as part of a physical exam to examine the spine through diagnosing process for thoracic kyphosis. Thoracic kyphosis is diagnosed when the thoracic spine's curve goes beyond 50 degrees [7]. The thoracic spine in located between the cervical and lumbar spine and forms the ribs cage by joining with the ribs. Therefore, thoracic kyphosis is characterized by a protracted scapulae and forward head posture, resulting in poor posture. It is necessary to understand the relationship between thoracic kyphosis with adjacent areas of the thoracic spine and there is a need for a physical examination method of analyzing for variable causes and conditions in order to accurately measure the problems associated with thoracic kyphosis.

The purpose of the study was to evaluate the diagnostic values of abdominal muscle thickness and sterno-costal angles as quantitative diagnostic indicators for young adults with rounded shoulders. This study hypothesized that the thoracic kyphotic curve will show a significant correlation with abdominal muscles thickness and sterno-costal angles in young adults with rounded shoulders.

\section{Methods}

\section{Participants}

Thirty-three health young males signed the informed consent forms according to institutional guidelines and participated in this study. Informed consent involved the details of the study and volunteers provided consent to participate before study enrollment. This study was approved by the institutional review board of Baekseok University (approved No. BUIRB-2019-HR-19) and the study procedures were conducted according to the Declaration of Helsinki.

The inclusion criteria of participants were as follows: a young male with kyphotic angle of 40 degrees or greater during the relaxed standing posture [8]; a person without any neurological diseases; a person without any orthopedic diseases; a person without any surgical history of the spine; and a person without rheumatoid arthritis. This study excluded those who had acute inflammation and other diseases that may affect the study.

\section{Study procedure}

This study was a observational cross-sectional study. The study measured the degree of thoracic kyphosis, the sterno-costal angle, and the thickness of abdominal muscles, including the rectus abdominis (RA), internal oblique (IO), external oblique (EO) and transverse abdominis (TrA) muscles. This study measured the thoracic kyphosis on two points, the 1st and 2nd thoracic spines (T1/T2), and over the 12th thoracic and 1st lumbar spines (T12/L1). First of all, the participants stood with their feet shoulder-width apart and gazed at the front line. With their placed their arms in comfortable position with their eyes looking towards the front, subjects were asked to swing their arms backwards and forwards and move their head into flexion-to-extension while gently performing deep breathing 3 times. Then, the participants stood in a comfortable position with arms relaxed and fixed on the side of their body. In order to measure the degree of thoracic vertebrae with two inclinometers, the assessor identified and marked the spinous process on the seventh cervical vertebrae, the 12th thoracic vertebrae and the first lumbar vertebrae. Using two inclinometers, the angles of inclination of the T1 and T2, and T12 and L1 was measured 3 times in succession, and the average of the angle was used for analyses (Figure 1) $[9,10]$.

This study measured the thickness of the RA, IO, EO, and TrA muscles using ultrasound imaging. The participants relaxed in a supine hook-lying position, with the hip and knees joint in flexion. The evaluator placed a pressure biofeedback unit (Chattanooga, Hixson, TN, USA) under the participants lumbar spine and inflated to $40 \mathrm{mmHg}$. To activate their abdominal muscles using the drawing-in maneuver, the participants took a relaxed breath in and out, held their breath out, and then drew in their lower abdomen without moving their

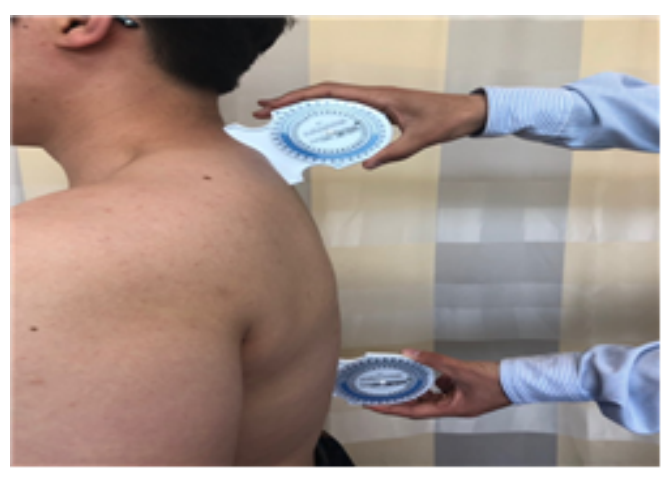

Figure 1. Measurement of the thoracic kyphosis. 

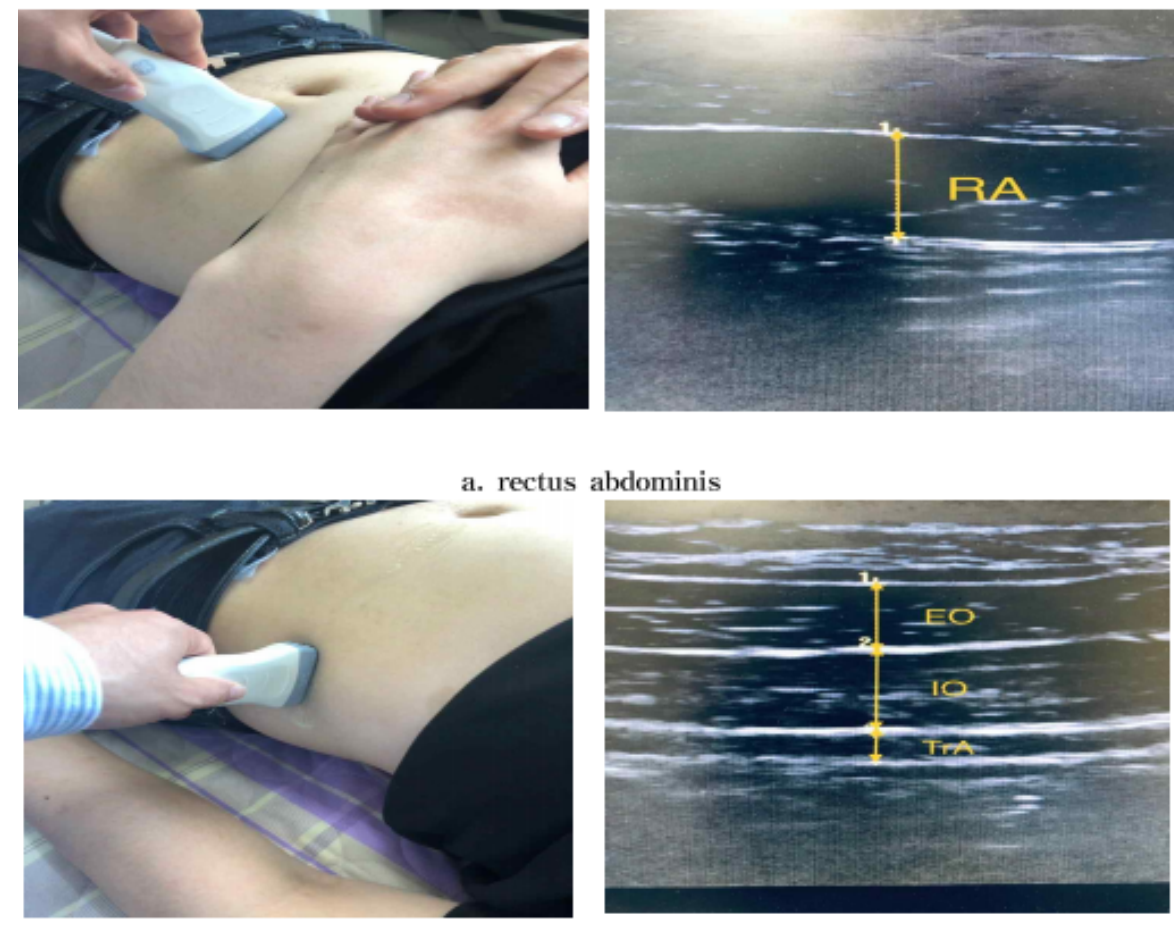

b. external oblique, internal oblique and transverse abdominis
Figure 2. Ultrasound imaging of abdominal muscles. (a) Rectus abdominis muscle. (b) External oblique, internal oblique and transverse abdominis muscles. spine. The evaluator used a blood pressure cuff to ensure maintenance of a consistent pelvic position. To measure the abdominal muscles TrA, IO, and EO, the UI transducer was transversely located across the right side of the abdominal wall over the anterior axillary line, midway between the 12th rib and the iliac crest. For the RA muscle, the transducer was placed 2-3 $\mathrm{cm}$ above the umbilicus, $2-3 \mathrm{~cm}$ from the midline. All images were captured directly at the end of the expiration, as determined by the visual inspection of the abdominal content. Three images of each muscle were taken at rest and the mean of the three measurements were used in the statistical analysis. Figure 2 shows the typical images of the abdominal muscles at rest.

The sterno-costal angle was measured by drawing an imaginary triangle on the abdomen. The upper vertex is the point where the borderline of both costal cartilage meets the midline of the xiphoid process of the sternum, the midline of human body. The lower vertex is the point where the perpendicular line from the half point of the clavicle meets the boundary of the costal cartilage. The lower vertex is two left and right. This study measured the angle formed by the midline of the human body and the line connecting the upper and lower vertices, the left and right sides, respectively. The examiner marked and photographed the vertices of the triangle and measured the sterno-costal angle using Image J (Figure 3).

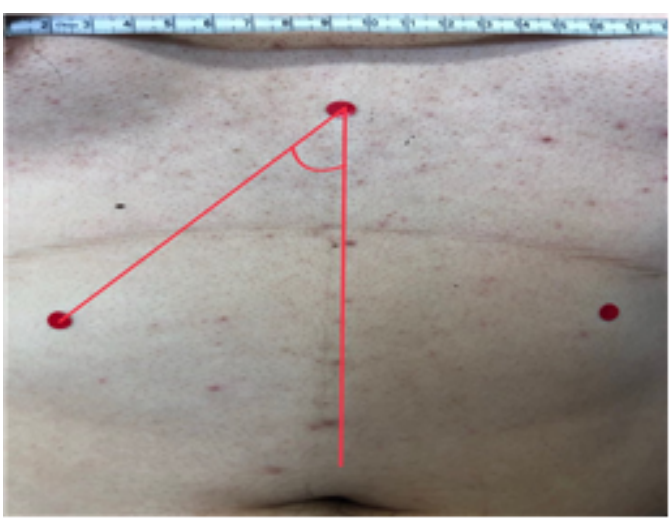

Figure 3. Sterno-costal angle measured by Image $\mathrm{J}$.

\section{Outcome measures}

To assess the relationship among the degree of thoracic kyphosis, abdominal muscle thickness, and sterno-costal angle, this study used three measurement tools, which were the inclinometer, ultrasound imaging, and Image J. Two gravity-dependent inclinometers (Isomed Inc. 975 SE Sandy Blvd, Portland, OR 97214, USA) were used to measure the degree of thoracic kyphosis. This study used ultrasound image (Ultrasound transducers ranging from 5 to $10 \mathrm{MHz}$ have been used) to assess the lateral abdominal muscles. 


\section{Data analysis}

All statistical analyses of this study were performed using PASW Statistics for Windows, Version 18.0 (SPSS Inc., Chicago, IL, USA). One-sample Kolmogrov-Smirnov test was used to assess the normality of distribution for the UI measurement of muscle thickness in all abdominal muscles at rest and to assess the normality of distribution for the degree of thoracic kyphosis at comfortable standing. Normal distribution was observed for variables. The association between thoracic kyphosis angle and abdominal muscles thickness were analyzed using the Pearson correlation coefficient and multiple regression analysis. A statistical level of significance was set at 0.05 .

\section{Results}

Table 1 illustrates the demographic characteristics including age, height and weight. All participants in this study were male. The mean age was 22.7 years. The mean height and weight were $173.5 \mathrm{~cm}$ and $73.9 \mathrm{~kg}$, respectively. The

Table 1. Common characteristics of participants in this study

$(\mathrm{N}=33)$

\begin{tabular}{lr}
\hline Variable & \multicolumn{1}{c}{ Value } \\
\hline Age $(\mathrm{y})$ & $22.7(4.8)$ \\
Height $(\mathrm{cm})$ & $173.5(5.1)$ \\
Weight $(\mathrm{kg})$ & $73.9(2.4)$ \\
\hline
\end{tabular}

Values are presented as mean (SD). dominant side was the right side in all subjects.

Table 2 shows the correlation among the thoracic kyphosis angle, thickness of abdominal muscles, and sterno-costal angle for participants in this study. There was a significant positive correlation with muscle thickness of the right EO ( $\mathrm{r}=0.931)$, and left $(\mathrm{r}=0.432)$, and $\operatorname{TrA}(\mathrm{r}=0.649)$. The thoracic kyphosis angle was also significantly negative correlation with sterno-costal angle at right side $(\mathrm{r}=-0.942)$ and sterno-costal angle at left side $(\mathrm{r}=-0.860)$. However, there was no significant correlation of the thoracic kyphosis angle with the muscle thickness of RA muscle and IO muscle at both side and $\operatorname{TrA}$ at left side.

Muscle thickness of EO at right side was significantly positive relationship with thoracic kyphosis angle, muscle thickness of TrA at right side $(r=0.657)$ and was significantly negative relationship with sterno-costal angle at both sides $(r=-0.975$ at right side and $r=-0.960$ at left side). Muscle thickness of TrA at right side was significantly positive correlation with thoracic kyphosis angle, and muscle thickness of EO at right side, but was not significantly negative correlation with RA at right and sterno-costal angle at both sides $(r=-0.609$ at right side and $r=-0.565$ at left side). Sterno-costal angle showed significantly negative correlation with the thoracic kyphosis angle $(r=-0.942$ and $\mathrm{r}=-0.860)$, thickness of $\mathrm{EO}$ at right side $(\mathrm{r}=-0.975$ and $\mathrm{r}=-0.960)$ and $\operatorname{TrA}$ at right side $(\mathrm{r}=-0.609$ and $\mathrm{r}=-0.565)$ (Table 2).

Table 2. Correlation among kyphosis angle, thickness of abdominal muscles, and sterno-costal angle in this study $(\mathrm{N}=33)$

\begin{tabular}{lccccccccccc}
\hline Variable & KA & RAR & EOR & IOR & TrAR & RAL & EOL & IOL & TrAL & SCAR & SCAL \\
\hline KA & 1 & -0.312 & $0.931^{* *}$ & 0.016 & $0.649 * *$ & -0.181 & $0.432^{*}$ & 0.242 & 0.262 & $-0.942^{* *}-0.860^{* *}$ \\
RAR & -0.312 & 1 & -0.274 & 0.233 & $-0.450^{* *}$ & $0.531^{* *}$ & -0.205 & -0.131 & -0.124 & 0.296 & 0.243 \\
EOR & $0.931^{* *}$ & -0.274 & 1 & 0.014 & $0.657^{* *}$ & -0.091 & $0.432^{*}$ & $0.381^{*}$ & 0.254 & $-0.975^{* *}-0.960^{* *}$ \\
IOR & 0.016 & 0.233 & 0.014 & 1 & 0.168 & 0.165 & -0.080 & 0.269 & -0.080 & 0.029 & 0.006 \\
TrAR & $0.649^{* *}$ & $-0.450^{* *}$ & $0.657^{* *}$ & 0.168 & 1 & -0.058 & 0.339 & 0.345 & 0.243 & $-0.609 * *-0.565^{* *}$ \\
RAL & -0.181 & $0.531^{* *}$ & -0.091 & 0.165 & -0.058 & 1 & -0.274 & 0.024 & -0.185 & 0.059 & -0.007 \\
EOL & $0.432^{*}$ & -0.205 & $0.432^{*}$ & -0.080 & 0.339 & -0.274 & 1 & 0.229 & 0.063 & -0.316 & -0.261 \\
IOL & 0.242 & -0.131 & $0.381^{*}$ & 0.269 & 0.345 & 0.024 & 0.229 & 1 & -0.035 & -0.282 & -0.338 \\
TrAL & 0.262 & -0.124 & 0.254 & -0.080 & 0.243 & -0.185 & 0.063 & -0.035 & 1 & -0.247 & -0.186 \\
SCAR & $-0.942^{* *}$ & 0.296 & $-0.975^{* *}$ & 0.029 & $-0.609^{* *}$ & 0.059 & -0.316 & -0.282 & -0.247 & 1 & $0.967 * *$ \\
SCAL & $-0.860^{* *}$ & 0.243 & $-0.960^{* *}$ & 0.006 & $-0.565^{* *}$ & -0.007 & -0.261 & -0.338 & -0.186 & $0.967 * *$ & 1 \\
\hline
\end{tabular}

KA: kyphosis angle, RAR: rectus abdominis right, EOR: external oblique right, IOR: internal oblique right, TrAR: transvers abdonimis right, RAL: rectus abdominis left, EOL: external oblique left, IOL: internal oblique left, TrAL: transvers abdonimis left, SCAR: sterno-costal angle right, SCAL: sterno-costal angle left.

${ }^{*} p<0.05,{ }^{* *} p<0.01$. 


\section{Discussion}

This study investigated the diagnostic values of abdominal muscle thickness and sterno-costal angle as the quantitative diagnostic indicators for rounded shoulders in young adults. The significant, main findings were as follows: (1) thoracic kyphosis angle showed good correlation with EO and $\operatorname{TrA}$ at right side, and the sterno-costal angle on both sides. (2) thickness of the EO muscle on the right side showed good correlation with the TrA muscle and sterno-costal angle on both sides. (3) thickness of TrA muscle on the right side showed good correlation with the kyphotic angle, EO muscle on the right side, and sterno-costal angle at both sides. (4) sterno-costal angle at both sides showed good correlation with the kyphotic angle and thickness of the EO and TrA muscles on the right side.

Excessive thoracic kyphosis is a common aged-related postural change in older adults and is associated with increased dysfunction of respiratory and diminished physical activities [11-15]. The rounded shoulder is no longer a dysfunction that only appears in the elderly. Modern young adults are reporting a lot of smartphone usage, and new dysfunctions are emerging through the use of smartphones in the youth as well as young adults. Previous studies have reported that browsing, texting, and emailing on smartphones except smartphone gaming consumes approximately three and a half hours of university-students' time per day [16]. The students maintain a stooped posture several hours a day, causing the development of postural syndromes, excessive thoracic kyphosis, which in turn results in incoordination of muscle contractions, postural muscle weakness, as well as postural muscle-fatigue early on $[15,17]$. The postural instability ultimately leads to the development of pain, stiffness and discomfort, and therefore it is important to prevent the development of postural syndromes, such as excessive thoracic kyphosis [18]. The physical exam for diagnosis of thoracic kyphosisw generally uses x-ray imaging, but the $\mathrm{x}$-ray shows only structural information, not the relationship between the skeletal and muscular system. There is also insufficient information about the mediating relationship among thoracic kyphosis, abdominal muscles and sterno-costal angles, although evidence is growing to suggest that the thoracic kyphosis angle is associated with forward head posture.

This study was conducted to suggest the diagnostic values of abdominal muscle thickness and sterno-costal angle as quantitative diagnostic indicators for thoracic kyphosis. The results of this study showed a good relationship among ab- dominal muscle thickness, sterno-costal angle, and the thoracic kyphotic angle. The kyphotic angle significantly increased as the sterno-costal angle decreased as well as the muscle thickness of the EO and TrA on the right side, which was the dominant side, but was not significantly related to the muscle thickness of others on the dominant side and all muscles on the non-dominant side. One previous study by Lorbergs et al. [19] investigated the cross-sectional and longitudinal associations of thoracic and lumbar muscle size and density with kyphosis in 1,087 women and men (mean age: 61 years). They suggested that the kyphosis severity is related to smaller trunk muscles with lower densities, such as the erector spinae, transversospinalis, and trapezius at the thoracic spine measured by CT images, but they did not measure the abdominal muscles size [19]. Another systematic review of previous studies evaluated previous research to determine if exercise can improve preexisting hyperkyphosis by decreasing the angle of thoracic kyphosis in adults aged 45 years and over. The review suggest the positive effects of exercise on hyperkyphosis in high-quality studies such as back extensor muscle strength, spinal extension mobility, postural awareness [20-22]. Since there is an uncoupling-force between back extensor muscles and abdominal muscles at the trunk, it can only be postulated that performing strengthening exercises of the back extensor muscles at the mid- trunk could lead to improvement of excessive thoracic kyphotic angle and would guess the properties of abdominal muscles and sterno-costal angle.

In conclusion, the relationship among the muscle thickness of the EO and TrA on the dominant side, the sterno-costal angle, and the thoracic kyphotic angle was found. However, our evidence can only apply to these two muscles since we did not examine other abdominal muscles. Our findings support that EO and TrA muscle thickness can serve as diagnostic indicators for thoracic kyphosis and that there is a negative relationship between thoracic kyphosis and sterno-costal angles. This study included only young male adults. Future studies are needed to include young female and male participations as well as older adults, and are needed to determine how strengthening the abdominal muscles contribute to preventing habitual posture-related changes in thoracic kyphosis.

\section{Conflict of Interest}

The authors declared no potential conflicts of interest with respect to the authorship and/or publication of this 
article.

\section{References}

1. Kisner C, Colby LA, Borstad S. Therapeutic exercise: foundations and techniques. 7th ed. Philadelphia (PA): F.A. Davis Co.; 2018.

2. Houglum PA, Bertoti DB, Brunnstrom S. Brunnstrom's clinical kinesiology. 6th ed. Philadelphia (PA): F.A. Davis Co.; 2012.

3. Carrier G, Fréchette E, Ugalde P, Deslauriers J. Correlative anatomy for the sternum and ribs, costovertebral angle, chest wall muscles and intercostal spaces, thoracic outlet. Thorac Surg Clin 2007; 17:521-8.

4. Cappello M, De Troyer A. On the respiratory function of the ribs. J Appl Physiol (1985). 2002;92:1642-6.

5. Porterfield JA, DeRosa C. Mechanical low back pain: perspectives in functional anatomy. 2nd ed. Philadelphia (PA): W.B. Saunders; 1998.

6. Quek J, Pua YH, Clark RA, Bryant AL. Effects of thoracic kyphosis and forward head posture on cervical range of motion in older adults. Man Ther 2013;18:65-71.

7. Barrett E, Lenehan B, O'sullivan K, Lewis J, McCreesh K. Validation of the manual inclinometer and flexicurve for the measurement of thoracic kyphosis. Physiother Theory Pract 2018; 34:301-8.

8. Katzman WB, Wanek L, Shepherd JA, Sellmeyer DE. Age-related hyperkyphosis: its causes, consequences, and management. J Orthop Sports Phys Ther 2010;40:352-60.

9. Hides JA, Miokovic T, Belavý DL, Stanton WR, Richardson CA. Ultrasound imaging assessment of abdominal muscle function during drawing-in of the abdominal wall: an intrarater reliability study. J Orthop Sports Phys Ther 2007;37:480-6.

10. Lewis JS, Valentine RE. Clinical measurement of the thoracic kyphosis. A study of the intra-rater reliability in subjects with and without shoulder pain. BMC Musculoskelet Disord 2010;11:39.

11. Kado DM, Prenovost K, Crandall C. Narrative review: hyperkyphosis in older persons. Ann Intern Med 2007;147:330-8.

12. Di Bari M, Chiarlone M, Matteuzzi D, Zacchei S, Pozzi C, Bellia $\mathrm{V}$, et al. Thoracic kyphosis and ventilatory dysfunction in un- selected older persons: an epidemiological study in Dicomano, Italy. J Am Geriatr Soc 2004;52:909-15.

13. Sinaki M, Brey RH, Hughes CA, Larson DR, Kaufman KR. Balance disorder and increased risk of falls in osteoporosis and kyphosis: significance of kyphotic posture and muscle strength. Osteoporos Int 2005;16:1004-10.

14. Takahashi T, Ishida K, Hirose D, Nagano Y, Okumiya K, Nishinaga $\mathrm{M}$, et al. Trunk deformity is associated with a reduction in outdoor activities of daily living and life satisfaction in community-dwelling older people. Osteoporos Int 2005; 16:2739.

15. Cochrane ME, Tshabalala MD, Hlatswayo NC, Modipana RM, Makibelo PP, Mashale EP, et al. The short-term effect of smartphone usage on the upper-back postures of university students. Cogent Eng 2019;6:1627752.

16. Berolo S, Wells RP, Amick BC 3rd. Musculoskeletal symptoms among mobile hand-held device users and their relationship to device use: a preliminary study in a Canadian university population. Appl Ergon 2011;42:371-8.

17. Chany AM, Marras WS, Burr DL. The effect of phone design on upper extremity discomfort and muscle fatigue. Hum Factors 2007;49:602-18.

18. Hoffman J, Gabel P. Expanding Panjabi's stability model to express movement: a theoretical model. Med Hypotheses 2013; 80:692-7.

19. Lorbergs AL, Allaire BT, Yang L, Kiel DP, Cupples LA, Jarraya $\mathrm{M}$, et al. A longitudinal study of trunk muscle properties and severity of thoracic kyphosis in women and men: the Framingham Study. J Gerontol A Biol Sci Med Sci 2019;74:420-7.

20. Bansal S, Katzman WB, Giangregorio LM. Exercise for improving age-related hyperkyphotic posture: a systematic review. Arch Phys Med Rehabil 2014;95:129-40.

21. Benedetti MG, Berti L, Presti C, Frizziero A, Giannini S. Effects of an adapted physical activity program in a group of elderly subjects with flexed posture: clinical and instrumental assessment. J Neuroeng Rehabil 2008;5:32.

22. Kuo YL, Tully EA, Galea MP. Sagittal spinal posture after Pilates- based exercise in healthy older adults. Spine (Phila Pa 1976) 2009;34:1046-51. 